\title{
Down Presymptomatic View of Dementia Characteristics
}

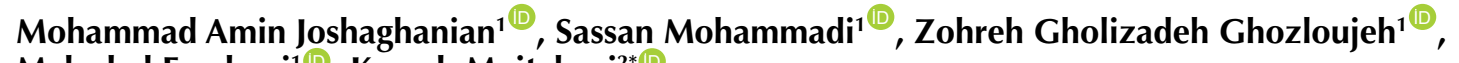 \\ Mehrdad Farahani1 ${ }^{\mathbb{D}}$, Kurosh Mojtabavi* ${ }^{*}$ \\ ${ }^{1}$ School of Medicine, Shahid Beheshti University of Medical Sciences, Tehran Iran \\ ${ }^{2}$ Cellular and Molecular Research Center \& Department of Physiology, School of Medicine, Guilan University of Medical \\ Sciences, Rasht, Iran
}

\begin{abstract}
Down syndrome (DS) is caused by complete or segmental chromosome 21 trisomy that results in neurodegeneration and progressive intellectual disability. Abnormal function in the prefrontal cortex, cerebellum, and hippocampus are the main reasons for cognitive deficits in DS that result in impaired cognitive function, delayed speech and language, learning and memory disability, and behavioral and emotional disorders. There is no specific treatment for DS, and our understanding of the mechanisms of the disorder is incomplete and causes to hamper the development of effective therapies regarding the development of neuropathology and memory loss in DS. Here, we review the literature on cognitive functioning, unique characteristics, environmental considerations, and recent findings on Alzheimer's disease in DS.

Keywords: Down syndrome (DS); Dementia; Alzheimer's Disease; Cognitive deficits, Neurodegeneration.
\end{abstract}

\author{
*Correspondence to \\ Kurosh Mojtabavi, Cellular and \\ Molecular Research Center \& \\ Department of Physiology, School \\ of Medicine, Guilan University of \\ Medical Sciences, Rasht, Iran. \\ Tel: 00989116511757; \\ Email: kourosh.mojtabavi@gmail. \\ com \\ Published online December 23, \\ 2019
}

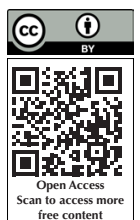

Citation: Joshaghanian MA, Mohammadi S, Gholizadeh Ghozloujeh Z, Farahani M, Mojtabavi K. Down presymptomatic view of dementia characteristics. Int Clin Neurosci J. 2020;7(1):1-5. doi:10.15171/icnj.2020.01.

\section{Introduction}

Down syndrome (DS) is one of the most common genetic disorders caused by the presence of 3 copies of chromosome 21 (Hsa21) instead of the usual two, which occurs during the meiotic cellular division phase. ${ }^{1}$

The worldwide prevalence of DS is 14 per 10000 live birth. However, this prevalence is different, based on socioeconomic factors. ${ }^{2,3}$ Three different types of DS consist of trisomy 21 or non-disjunction (most common), Robertsonian translocation, and mosaicism. ${ }^{4}$

DS impair normal brain development, cause a small cerebellum, frontal, and temporal cortex, as well as simplified appearances of sulci and a narrow superior temporal gyrus. ${ }^{5}$ High-resolution MRI in subjects with DS demonstrates lower volume in different brain structures such as the cerebellum, cingulate gyrus, frontal cortex, superior temporal cortex, and hippocampus, compared to the normal population. ${ }^{6}$

These changes could be the main reason for various range of intellectual abnormalities, including cognitive impairment and intellectual disabilities and Alzheimer's disease. Although the different medical aspect of DS is well-known, however properties of Alzheimer's disease in subjects with DS has not been well discussed so far.

\section{Methods}

\section{Search Strategy}

We performed an updated review on relevant research relating DS and cognitive function by an electronic literature search in the health databases among English articles published before 2019. A total of 6 research databases, including PubMed, Scopus, EMBSCO, CINAHL, ISC, and Cochrane Library were searched for this review by using keywords: 'Down syndrome," "cognitive dysfunction," "cognitive impairment," Dementia" and "Alzheimer's disease." The result included 40 articles selected based upon their relevance to DS and Alzheimer's disease.

\section{Pathophysiology}

Dementia is common in adults with DS. Recent studies indicate that Alzheimer's disease neuropathological changes occur almost in all people with DS after forth decades. $^{7}$ Also, data show that nearly $40 \%$ of people with DS known as the case of dementia after the 60s. ${ }^{7}$

Increased risk for developing early-onset Alzheimer's disease is associated with overexpressed on chromosome 21. Amyloid precursor protein (APP) is an integral membrane protein expressed in many tissues and 
concentrated in the synapses of neurons. ${ }^{8,9}$ This protein yields the toxic amyloid protein that forms plaques in the brain and damages brain cells, and their connections coded for chromosome 21. In DS, due to an extra copy of chromosome 21, AAP production is 1.5 times as many apps as the normal population. These results in the excess build-up of the abnormal amyloid breakdown.?

Presentation of dementia is different in DS, and symptoms related to frontal lobe deterioration like personality and behavior changes are more notable. ${ }^{10}$,

${ }^{11}$ It should consider that the behavioral and emotional changes in DS may occur because of the complexity of Alzheimer's disease diagnosis in people with DS in comparison with the normal population. ${ }^{12}$

Increased prevalence of dementia in older people with DS has implications not only for individuals concerned but will also demand changes in service provision and impact in terms of increased caregiver stress and economic cost. ${ }^{13}$

\section{Clinical Symptoms}

Due to the difficulty of dementia diagnosis in DS, the investigator attempts to explain the standardized assessment methods. Recently developed instruments based on either informant interview or direct cognitive assessment. ${ }^{14,15}$

Possible reasons for delayed diagnosis of Alzheimer's disease in people with DS, including (1) Inherent difficulties in diagnosing cognitive decline in those with a pre-existing cognitive impairment. (2) Lake of appropriate standard screening tools for assessing cognitive impairment in this population. (3) Difficulty with determining of subtle cognitive decline, particularly in people who have not attained many skills and in those living in a residential setting with low environmental demands. ${ }^{16-18}$

In the last decades, physicians used their clinical judgment and criteria from the International Classification of Disease (ICD) and Diagnostic Statistical Manual of Mental Disorders-IV text revision (DSM-IV-TR) to establish cognitive impairment. ${ }^{19}, 20$ This judgment was most accurate in identifying previously diagnosed cases compared with ICD-10 criteria and DSM-IV-TR criteria. Over time the DSM-IV has recently been replaced by the DSM-5, which introduced a new diagnostic category for the mild neurocognitive disorder, which may help to make earlier diagnoses in DS. ${ }^{20}$

\section{Comorbidities}

DS is associated with a wide range of medical conditions such as cardiac defects, leukemia, gastrointestinal issues, vision and hearing issues, dental issues, thyroid disease, obstructive sleep apnoea, epilepsy, and Alzheimer's disease. ${ }^{21}$ The prevalence of dementia has not any correlation with these conditions does not change significantly in the presence of dementia, and physicians should be aware of their emergence irrespective of cognitive decline. ${ }^{8}$

It has well known that epilepsy occurrence is more common in DS in compare than in comparison with the general population. ${ }^{22,23}$ The exact frequency of epilepsy in DS is unclear; however, more recent studies have reported a prevalence of seizures $1 \%$ to $13 \% .^{24}$

Epilepsy is more common in those with DS who suffer from dementia. This prevalence is more than $70 \%$ in a group with dementia. On the other hand, epilepsy diagnosis is a significant predictor of morbidity and mortality in people with DS. ${ }^{25,} 26$ The incidence of cardiovascular events in DS is nearly $25 \%$ in comparison with controls. ${ }^{27}$ Haemorrhagic strokes were more common in people with DS. This condition is mostly because of cerebral amyloid angiopathy due to the deposition of amyloid-beta within the walls of cerebral blood vessels, which results in intracerebral hemorrhage. ${ }^{28}$

\section{Diagnosis}

Nowadays, several tests have recently been shown to be useless in case of severing intellectual disability or dementia. This issue displays the importance of the need to develop more specific neurocognitive tools for people with DS. However, object memory, semantic verbal fluency, the cued recall task, Tower of London, the CANTAB paired associate learning and simple reaction time tasks and visuomotor precision tasks are between the suitable cognitive test for distinguishing between those with and without dementia and tracking dementia-related decline. ${ }^{8,29-32}$ Validation of the NIH Toolbox (HealthMeasures, Evanston, Illinois, USA) Cognitive Battery for intellectual disability found that Flanker inhibition/ attention tasks, picture vocabulary, oral reading, and picture sequence memory tasks were accessible to those with intellectual disability.

In contrast, dimensional change card sort, pattern comparison, and list sorting tasks showed large floor effects, limiting their suitability as trial outcome measures. ${ }^{33}$ However, this study focused on a young sample, including individuals with Fragile $\mathrm{X}$ syndrome and idiopathic intellectual disability; thus, the suitability of these tasks in older adults with DS remains unclear. ${ }^{34}$ The Rapid Assessment for Developmental Disabilities battery and the NeuroTrax (Mindstreams, Newark, NJ, USA) Moderate to Severe Impairment Assessment Battery have also proposed as suitable tools for assessing cognitive function in those with DS. However, neither study reported full performance data. ${ }^{35} \mathrm{~A}$ novel informant questionnaire addressing executive function, memory, and language skills in DS was found to have high internal consistency, test-retest reliability, and interrater reliability. This questionnaire could reliably discriminate between those with and without dementia, but showed no significant effects of age or sex, suggesting it could be useful for tracking cognitive decline, mainly where individuals are unable to engage with standard cognitive 
assessments. ${ }^{36}$

Recent studies showed that behavioral and psychological symptoms and executive dysfunction might precede memory impairment in DS dementia., ${ }^{3,10,37}$ Immediate memory impairment is one of the earliest signs of dementia in people with DS. ${ }^{38}$ However, more studies are necessary to identify the sequence of early changes in DS. It should consider that not all cases of cognitive decline in DS are the result of dementia.

Neuroimaging is a useful tool for evaluating biomarkers associated with the progression of dementia in people with DS. Positron emission tomography scans with amyloid-beta-binding compounds showed amyloid deposition and its association with dementia in DS. In a study by Sabbagh et al, mean standard uptake value ratios (SUVRs) assessed as the primary outcome measure of fibrillar amyloid-beta burden in individuals with DS. Their results showed significant group differences in mean SUVRs reported, with uptake higher in DS individuals compared with controls, and greater still in those with DS and dementia..$^{39,40}$ Another study using PET demonstrated that standard uptake value ratios binding correlated with age, but not with cognitive decline. ${ }^{41}$ Annus et al showed Pittsburgh compound B (another amyloid beta-binding compound) binding first in the striatum around age 40 years that significantly increased in several brain regions by age 50 years. They also found that $\mathrm{PiB}$ binding significantly correlated with diagnostic status and history of cognitive decline. ${ }^{42}$ These studies suggest that PET imaging techniques could be useful to stage DS in the presymptomatic period based on amyloid positive condition on scans and to control the specific changes associated with the progression of Alzheimer's disease. Other investigations, such as of EEG biomarkers, revealed a correlation between cognitive decline and theta slowing. ${ }^{43}$

\section{Treatment Options}

In the case of early diagnosis, effective therapeutic intervention such as acetylcholinesterase inhibitors and psycho-social supports, including appropriate support for carers, can be helpful.

Acetylcholine esterase inhibitors could be beneficial in individuals with DS who have dementia; however, there is a lake of enough evidence for its efficacy. ${ }^{44}$

Natural DYRK1A inhibitor epigallocatechin-3-gallate (EGCG), is useful in Alzheimer's disease in DS, as the DYRK1A gene situated on chromosome $21 .{ }^{45}$ In a randomized placebo-controlled trial on EGCG, after 12 months, in adults with DS, those in the treatment arm had significantly higher scores in measures of visual recognition memory, inhibitory control, and adaptive behaviour. ${ }^{45}$ Another randomized placebo-controlled trial showed no difference between drug and placebo on the primary outcome (a brief praxis test), dementia rates, or secondary outcomes in individuals with DS with 1000
IU of vitamin E orally twice daily for three years. ${ }^{46}$

Cooper et al. reported a randomized placebo-controlled trial of simvastatin to prevent dementia in people with DS. Although the results were meaningful, the trial was too small to demonstrate the benefit of the simvastatin. ${ }^{8}$

\section{Conclusion}

The unique presentation of Alzheimer's disease in individuals with DS made these populations as specific community unique population for researching and developing clinical trials of drugs for primary prevention of Alzheimer's disease. Further work is necessary to understand the progression of the disorder and its relationship with the development of symptoms during the presymptomatic period of Alzheimer's disease in DS.

\section{Conflict of Interest Disclosures}

The authors declare that they have no conflict of interests.

\section{Ethical Statement}

Not applicable.

\section{References}

1. Roizen NJ, Patterson D. Down's syndrome. Lancet. 2003;361(9365):1281-9. doi: 10.1016/s0140-6736(03)12987-x.

2. Presson AP, Partyka G, Jensen KM, Devine OJ, Rasmussen SA, McCabe LL, et al. Current estimate of Down syndrome population prevalence in the United States. J Pediatr. 2013;163(4):1163-8. doi: 10.1016/j.jpeds.2013.06.013.

3. Weijerman $M E$, van Furth $A M$, Vonk Noordegraaf $A$, van Wouwe JP, Broers CJ, Gemke RJ. Prevalence, neonatal characteristics, and first-year mortality of Down syndrome: a national study. J Pediatr. 2008;152(1):15-9. doi: 10.1016/j. jpeds.2007.09.045.

4. Perkins A. The lowdown on Down syndrome. Nursing Made Incredibly Easy. 2017;15(2):40-6. doi: 10.1097/01. NME.0000511841.85763.77

5. Matthews DC, Lukic AS, Andrews RD, Marendic B, Brewer J, Rissman RA, et al. Dissociation of Down syndrome and Alzheimer's disease effects with imaging. Alzheimers Dement (N Y). 2016;2(2):69-81. doi: 10.1016/j.trci.2016.02.004.

6. Pearlson GD, Breiter SN, Aylward EH, Warren AC, Grygorcewicz M, Frangou S, et al. MRI brain changes in subjects with Down syndrome with and without dementia. Dev Med Child Neurol. 1998;40(5):326-34.

7. Wiseman FK, Al-Janabi T, Hardy J, Karmiloff-Smith A, Nizetic D, Tybulewicz VL, et al. A genetic cause of Alzheimer disease: mechanistic insights from Down syndrome. Nat Rev Neurosci. 2015;16(9):564-74. doi: 10.1038/nrn3983.

8. Cooper SA, Ademola T, Caslake M, Douglas E, Evans J, Greenlaw N, et al. Towards onset prevention of cognition decline in adults with Down syndrome (The TOP-COG study): a pilot randomised controlled trial. Trials. 2016;17:370. doi: 10.1186/s13063-016-1370-9.

9. Lotfinia M, Lotfinia AA, Khodaie B, Ahmadi M, Asaadi S, Jafarian M. Propagation of spreading depression: a review of different hypothesis. The Neuroscience Journal of Shefaye Khatam. 2014;2(3):53-64. [Persian].

10. Ball SL, Holland AJ, Treppner P, Watson PC, Huppert FA. Executive dysfunction and its association with personality and behaviour changes in the development of Alzheimer's 
disease in adults with Down syndrome and mild to moderate learning disabilities. Br J Clin Psychol. 2008;47(Pt 1):1-29. doi: 10.1348/014466507×230967.

11. Lott IT, Dierssen M. Cognitive deficits and associated neurological complications in individuals with Down's syndrome. Lancet Neurol. 2010;9(6):623-33. doi: 10.1016/ s1474-4422(10)70112-5.

12. Ball SL, Holland AJ, Hon J, Huppert FA, Treppner P, Watson PC. Personality and behaviour changes mark the early stages of Alzheimer's disease in adults with Down's syndrome: findings from a prospective population-based study. Int J Geriatr Psychiatry. 2006;21(7):661-73. doi: 10.1002/gps.1545.

13. Bittles AH, Bower C, Hussain R, Glasson EJ. The four ages of Down syndrome. Eur J Public Health. 2007;17(2):221-5. doi: 10.1093/eurpub/ckl103.

14. Deb S, Braganza J. Comparison of rating scales for the diagnosis of dementia in adults with Down's syndrome. J Intellect Disabil Res. 1999;43 (Pt 5):400-7. doi: 10.1046/j.13652788.1999.043005400.x.

15. Deb S, Hare M, Prior L. Symptoms of dementia among adults with Down's syndrome: a qualitative study. J Intellect Disabil Res. 2007;51(Pt 9):726-39. doi: 10.1111/j.13652788.2007.00956.x.

16. Tsao R, Kindelberger C, Fréminville B, Touraine R, Gerald B. Variability of the aging process in dementia-free adults with Down syndrome. Am J Intellect Dev Disabil. 2015;120(1):315. doi: 10.1352/1944-7558-120.1.3.

17. Holland AJ, Hon J, Huppert FA, Stevens F, Watson P. Population-based study of the prevalence and presentation of dementia in adults with Down's syndrome. Br J Psychiatry. 1998;172:493-8. doi: 10.1192/bjp.172.6.493.

18. Tassé MJ, Navas Macho P, Havercamp SM, Benson BA, Allain DC, Manickam K, et al. Psychiatric conditions prevalent among adults with Down syndrome. J Policy Pract Intellect Disabil. 2016;13(2):173-80. doi: 10.1111/jppi.12156.

19. Vahia VN. Diagnostic and statistical manual of mental disorders 5: a quick glance. Indian J Psychiatry. 2013;55(3):220-3. doi: 10.4103/0019-5545.117131.

20. Fletcher RJ, Barnhill J, McCarthy J, Strydom A. From DSM to DM-ID. J Ment Health Res Intellect Disabil. 2016;9(3):189204. doi: 10.1080/19315864.2016.1185324.

21. Jaruratanasirikul S, Limpitikul W, Dissaneevate P, Booncharoen P, Tantichantakarun P. Comorbidities in Down syndrome livebirths and health care intervention: an initial experience from the birth defects registry in Southern Thailand. World J Pediatr. 2017;13(2):152-7. doi: 10.1007/s12519-016-0093-z.

22. McCarron M, McCallion P, Reilly E, Mulryan N. A prospective 14-year longitudinal follow-up of dementia in persons with Down syndrome. J Intellect Disabil Res. 2014;58(1):61-70. doi: $10.1111 /$ jir.12074.

23. Alexander M, Petri H, Ding Y, Wandel C, Khwaja O, Foskett N. Morbidity and medication in a large population of individuals with Down syndrome compared to the general population. Dev Med Child Neurol. 2016;58(3):246-54. doi: 10.1111/ dmcn.12868.

24. Arya R, Kabra M, Gulati S. Epilepsy in children with Down syndrome. Epileptic Disord. 2011;13(1):1-7. doi: 10.1684/ epd.2011.0415.

25. Lott IT, Doran E, Nguyen VQ, Tournay A, Movsesyan N, Gillen DL. Down syndrome and dementia: seizures and cognitive decline. J Alzheimers Dis. 2012;29(1):177-85. doi: 10.3233/ jad-2012-111613.

26. Taghdiri MM, Omidbeigi M, Asaadi S, Azargashb E, Ghofrani
M. Childhood Epilepsy; Prognostic Factors in Predicting the Treatment Failure. Iran J Child Neurol. 2017;11(1):21-8.

27. Sobey CG, Judkins CP, Sundararajan V, Phan TG, Drummond GR, Srikanth VK. Risk of Major Cardiovascular Events in People with Down Syndrome. PLoS One. 2015;10(9):e0137093. doi: 10.1371/journal.pone.0137093.

28. Buss L, Fisher E, Hardy J, Nizetic D, Groet J, Pulford L, et al. Intracerebral haemorrhage in Down syndrome: protected or predisposed? F1000Res. 2016;5. doi: 10.12688/ f1000research.7819.1.

29. de Sola S, de la Torre R, Sanchez-Benavides G, Benejam B, Cuenca-Royo A, Del Hoyo L, et al. A new cognitive evaluation battery for Down syndrome and its relevance for clinical trials. Front Psychol. 2015;6:708. doi: 10.3389/fpsyg.2015.00708.

30. Sinai A, Hassiotis A, Rantell K, Strydom A. Assessing Specific Cognitive Deficits Associated with Dementia in Older Adults with Down Syndrome: Use and Validity of the Arizona Cognitive Test Battery (ACTB). PLoS One. 2016;11(5):e0153917. doi: 10.1371/journal.pone.0153917.

31. Startin CM, Hamburg S, Hithersay R, Davies A, Rodger E, Aggarwal N, et al. The LonDownS adult cognitive assessment to study cognitive abilities and decline in Down syndrome. Wellcome Open Res. 2016;1:11. doi: 10.12688/ wellcomeopenres.9961.1.

32. Liogier d'Ardhuy X, Edgin JO, Bouis C, de Sola S, Goeldner C, Kishnani $\mathrm{P}$, et al. Assessment of Cognitive Scales to Examine Memory, Executive Function and Language in Individuals with Down Syndrome: Implications of a 6-month Observational Study. Front Behav Neurosci. 2015;9:300. doi: 10.3389/ fnbeh.2015.00300.

33. Hessl D, Sansone SM, Berry-Kravis E, Riley K, Widaman KF, Abbeduto L, et al. The NIH Toolbox Cognitive Battery for intellectual disabilities: three preliminary studies and future directions. J Neurodev Disord. 2016;8(1):35. doi: 10.1186/ s11689-016-9167-4.

34. Walsh DM, Doran E, Silverman W, Tournay A, Movsesyan $\mathrm{N}$, Lott IT. Rapid assessment of cognitive function in down syndrome across intellectual level and dementia status. J Intellect Disabil Res. 2015;59(11):1071-9. doi: 10.1111/ jir.12200.

35. Gutman M, Moskovic E, Jeret JS. Computerised cognitive testing of individuals with Down's syndrome and Alzheimer's disease. J Intellect Disabil Res. 2016;60(2):179-81. doi: 10.1111/jir.12227.

36. Startin CM, Rodger E, Fodor-Wynne L, Hamburg S, Strydom A. Developing an Informant Questionnaire for Cognitive Abilities in Down Syndrome: The Cognitive Scale for Down Syndrome (CS-DS). PLoS One. 2016;11(5):e0154596. doi: 10.1371/journal.pone.0154596.

37. Asaadi S, Ashrafi F, Omidbeigi M, Nasiri Z, Pakdaman H, Amini-Harandi A. Persian version of frontal assessment battery: correlations with formal measures of executive functioning and providing normative data for Persian population. Iran J Neurol. 2016;15(1):16-22.

38. Blok JB, Scheirs JGM, Thijm NS. Personality and behavioural changes do not precede memory problems as possible signs of dementia in ageing people with Down syndrome. Int J Geriatr Psychiatry. 2017;32(12):1257-63. doi: 10.1002/gps.4606.

39. Sabbagh MN, Chen K, Rogers J, Fleisher AS, Liebsack C, Bandy D, et al. Florbetapir PET, FDG PET, and MRI in Down syndrome individuals with and without Alzheimer's dementia. Alzheimers Dement. 2015;11(8):994-1004. doi: 10.1016/j. jalz.2015.01.006. 
40. Jennings D, Seibyl J, Sabbagh M, Lai F, Hopkins W, Bullich $S$, et al. Age dependence of brain beta-amyloid deposition in Down syndrome: An [18F] florbetaben PET study. Neurology. 2015;84(5):500-7. doi: 10.1212/wnl.0000000000001212.

41. Lin AL, Powell D, Caban-Holt A, Jicha G, Robertson W, Gold BT, et al. (1)H-MRS metabolites in adults with Down syndrome: Effects of dementia. Neuroimage Clin. 2016;11:728-35. doi: 10.1016/j.nicl.2016.06.001

42. Annus $\mathrm{T}$, Wilson LR, Hong YT, Acosta-Cabronero J, Fryer TD, Cardenas-Blanco A, et al. The pattern of amyloid accumulation in the brains of adults with Down syndrome. Alzheimers Dement. 2016;12(5):538-45. doi: 10.1016/j. jalz.2015.07.490.

43. Salem LC, Sabers A, Kjaer TW, Musaeus C, Nielsen MN, Nielsen AG, et al. Quantitative Electroencephalography as a Diagnostic Tool for Alzheimer's Dementia in Adults with Down Syndrome. Dement Geriatr Cogn Dis Extra. 2015;5(3):404-13. doi: 10.1159/000438857.

44. Eady N, Courtenay K, Strydom A. Pharmacological management of behavioral and psychiatric symptoms in older adults with intellectual disability. Drugs Aging. 2015;32(2):95102. doi: 10.1007/s40266-014-0236-7.

45. De la Torre R, De Sola S, Pons M, Duchon A, de Lagran MM, Farre $M$, et al. Epigallocatechin-3-gallate, a DYRK1A inhibitor, rescues cognitive deficits in Down syndrome mouse models and in humans. Mol Nutr Food Res. 2014;58(2):278-88. doi: 10.1002/mnfr.201300325.

46. Sano M, Aisen PS, Andrews HF, Tsai WY, Lai F, Dalton AJ. Vitamin $E$ in aging persons with Down syndrome: a randomized, placebo-controlled clinical trial. Neurology. 2016;86(22):2071-6. doi: 10.1212/wnl.0000000000002714. 